\title{
Histological complete response to a combined docetaxel/cisplatin/fluorouracil neoadjuvant chemotherapy for T4 stage gastric adenocarcinoma
}

\author{
Ming gao Guo*, Qi Zheng, Jian zhong Di and Zhe Yang
}

\begin{abstract}
Local advanced gastric carcinoma has a very poor prognosis. When a T4 gastric carcinoma has invaded the surrounding tissues and organs, curative resection is unlikely. We present here a case of a 63-year-old woman with a T4 unresectable gastric adenocarcinoma. She underwent two 3-week cycles of docetaxel/cisplatin/fluorouracil chemotherapy, followed by radical gastric resection. Each cycle consisted of $75 \mathrm{mg} / \mathrm{m}^{2}$ docetaxel and $75 \mathrm{mg} / \mathrm{m}^{2}$ cisplatin on day 1 , and $200 \mathrm{mg} / \mathrm{m}^{2}$ leucovorin and $500 \mathrm{mg} / \mathrm{m}^{2}$ fluorouracil on days 1 through 5 . The patient exhibited a complete histologic response. Our results indicate that docetaxel/cisplatin/fluorouracil neoadjuvant chemotherapy is a promising method of treatment for advanced gastric cancer.
\end{abstract}

Keywords: Gastric cancer, neoadjuvant chemotherapy, docetaxel, cisplatin, fluorouracil

\section{Background}

Gastric cancer is one of the most common malignancies and leading cause of cancer mortality worldwide, with an estimated 900,000 new cases and more than 700,000 deaths in 2006 alone [1,2]. Radical gastrectomy with extended lymphadenectomy is now recognized as the only potentially curative treatment. Patients who present with stage III or IV disease, however, are not eligible for curative resection and thus have an especially poor prognosis. Moreover, local recurrence or distant metastasis can develop in a short time even after curative resection [3]. Over the past decade, an increasing number of reports have shown that neoadjuvant chemotherapy may be useful for patients with advanced $\mathrm{T}$ - and N-category lesions, possibly resulting in downstaging of tumors, improved rate of primary tumor resection with negative surgical margins, and early treatment of micrometastatic disease. We report here a case of a patient with a T4 unresectable gastric adenocarcinoma who exhibited a complete histologic response after docetaxel-based neoadjuvant chemotherapy.

\footnotetext{
* Correspondence: guominggao203@hotmail.com

Department of Surgery, the Six People's Hospital of Shanghai, Shanghai Jiaotong University, Shanghai 200233, China
}

\section{Case presentation}

A 63-year-old woman presented to our local hospital because of epigastric pain. Endoscopic examination revealed a $45 \times 52 \mathrm{~mm}$ irregular lesion in the lesser curvature of the antrum of the stomach. A biopsy indicated undifferentiated adenocarcinoma (Figure 1A). Abdominal computed tomography (CT) showed thickening of the gastric wall. Enlarged metastatic lymph nodes could not be found. Obliteration of the fat planes between the gastric tumor and adjacent organs indicated a T4 tumor [4,5] (Figure 2A). A diagnosis of advanced gastric cancer, T4 $\mathrm{N}_{\mathrm{X}} \mathrm{M}_{0}$, Stage IIIA or Ic, was made in accordance with the current International Union Against Cancer TNM staging system. Because of the difficulty of performing a radical operation, we recommended that the patient undergo chemotherapy.

Neoadjuvant chemotherapy was administered using docetaxel, cisplatin, fluorouracil, and leucovorin. On day $1,75 \mathrm{mg} / \mathrm{m}^{2}$ docetaxel and $75 \mathrm{mg} / \mathrm{m}^{2}$ cisplatin were administered intravenously. On days 1 through final day of the cycle $500 \mathrm{mg} / \mathrm{m}^{2}$ fluorouracil and $200 \mathrm{mg} / \mathrm{m}^{2}$ leucovorin were administered. One cycle lasted 3 weeks, and two cycles were performed. Another CT scan was performed 2 weeks later. The results showed dramatic

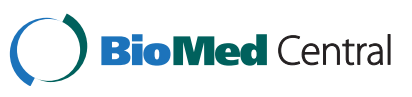

(C) 2014 Guo et al.; licensee BioMed Central Ltd. This is an Open Access article distributed under the terms of the Creative Commons Attribution License (http://creativecommons.org/licenses/by/2.0), which permits unrestricted use, distribution, and reproduction in any medium, provided the original work is properly credited. 

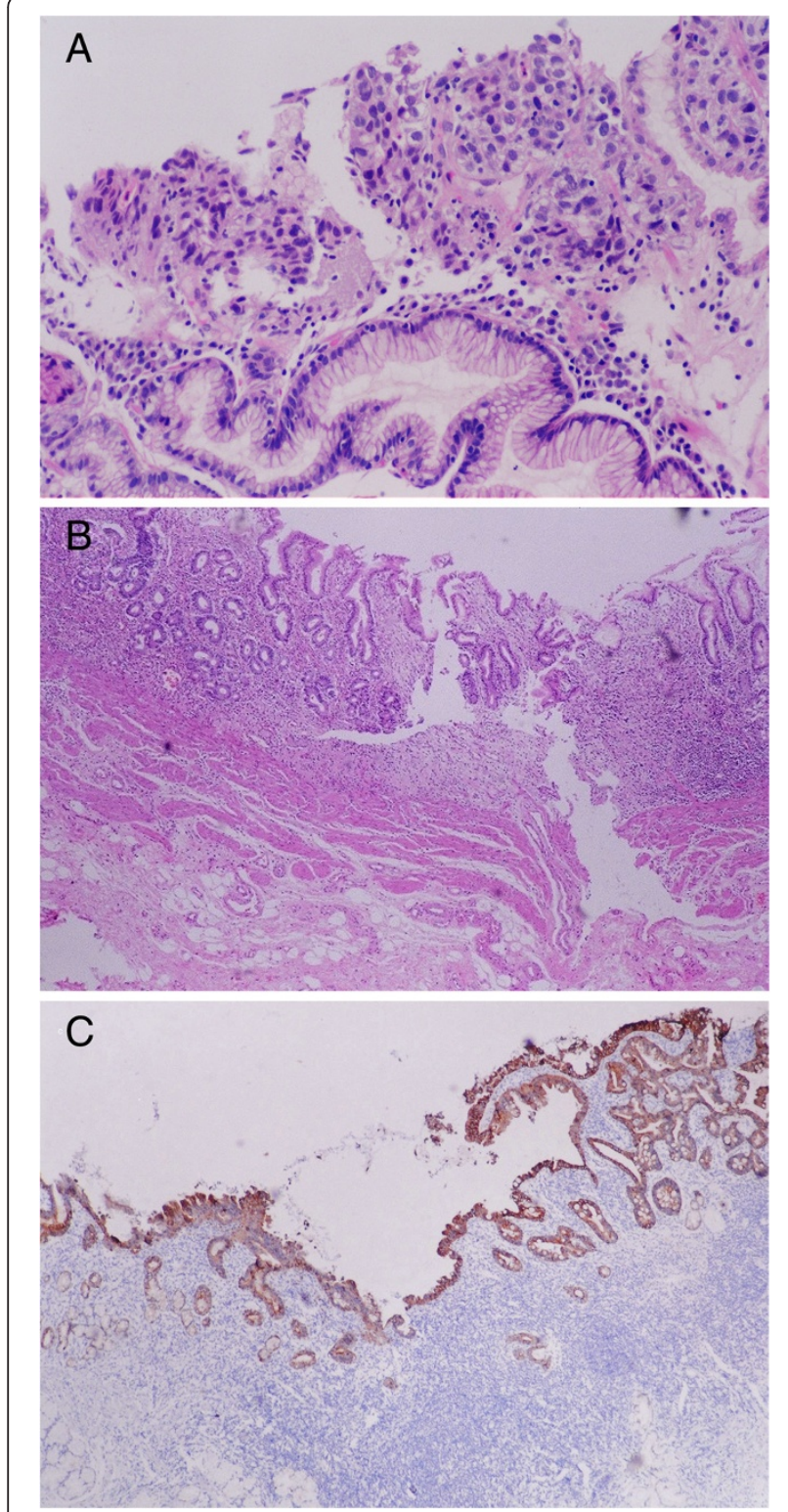

Figure 1 Tumor and histopathological features. (A) Biopsy indicated undifferentiated adenocarcinoma. (B) Microscopic examination of the excised specimen showed no remaining gastric adenocarcinoma cells and coverage of the lesion with regenerative mucosa. Gland degeneration was seen in the mucosa. Fibrosis and lymph follicle formation were observed in the gastric wall. (C) No gastric adenocarcinoma cell remnants were detected even with immunohistochemistry staining for CK20.

reduction of the primary lesion and clarification of the fat planes between the gastric tumor and adjacent organs (Figure 2B). Enlarged metastatic lymph nodes and ascites were not found.

Surgery was performed 4 weeks after neoadjuvant chemotherapy. No overt peritoneal metastases were found, and the gastric tumor was not obvious. The surgical procedure was distal partial gastrectomy with a $5-\mathrm{cm}$

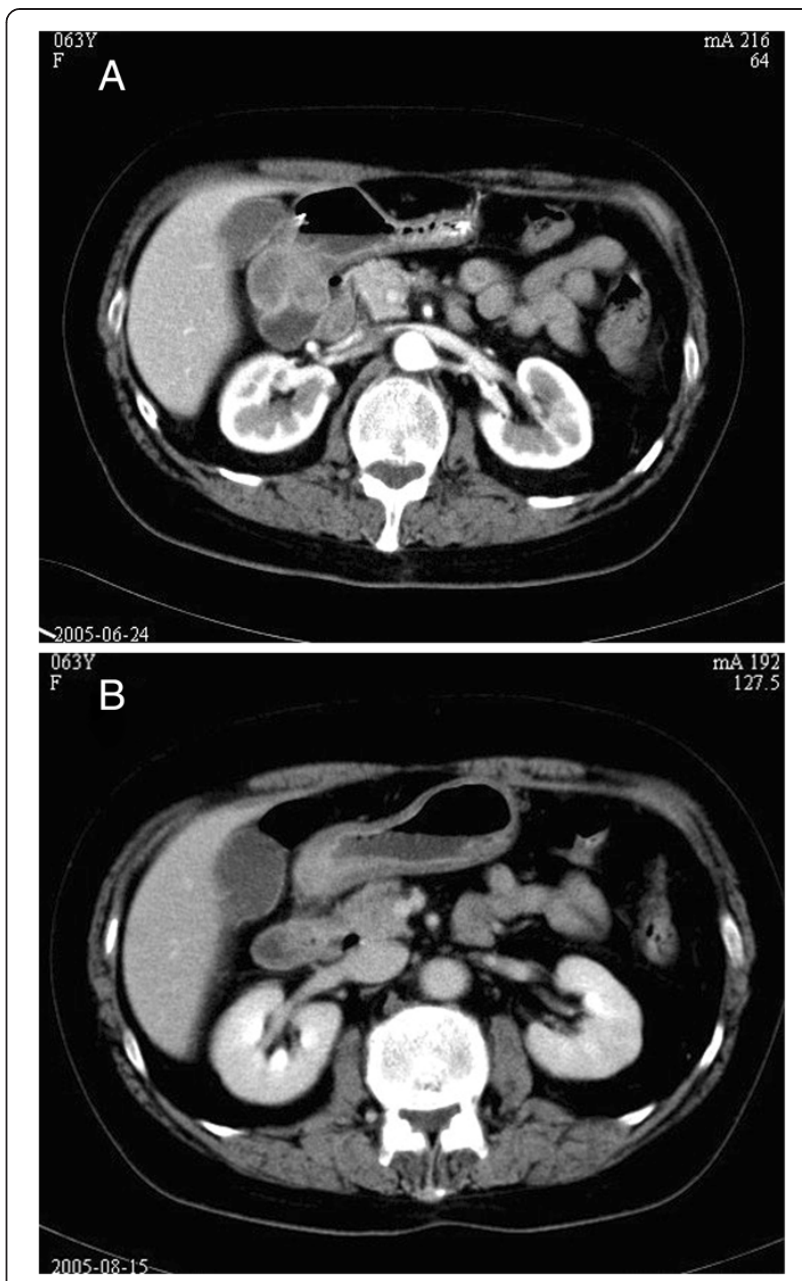

Figure 2 Computed tomography of the gastric wall. (A) Abdominal computed tomography $(C T)$ scans revealed thickening of the gastric wall. Obliteration of the fat planes between the gastric tumor and adjacent organs indicated a T4 tumor. (B) CT scans after two courses of chemotherapy showed dramatic reduction of the primary lesion and clarification of the fat planes.

margin of safety. A D2 lymph node dissection according to the Japanese Research Society for Gastric Cancer (JRSGC) guidelines [6] was performed, and 21 lymph nodes were dissected. The Billroth II method was used for reconstruction of the alimentary tract.

Macroscopic examination revealed an irregular lesion extending to proprietary muscle, measuring $10 \times 12 \mathrm{~mm}$, in the lesser curvature of the excised gastric specimen. Microscopic examination indicated that no gastric adenocarcinoma cells remained and the lesion was covered with regenerative mucosa. Gland degeneration was seen in the mucosa. Fibrosis and lymph follicle formation were observed from the submucosa to the subserosa (Figure 1B). No gastric adenocarcinoma cell remnants were detected even with immunohistochemistry staining for CK20 (Figure 1C). No lymph node metastasis was found on 
pathologic examination. No additional chemotherapy was performed after surgery. Follow-up examination was conducted every 6 months for a total of 8 years. The patient remained healthy, with no tumor recurrence or metastasis. She was considered to have had a complete histologic response to treatment with neoadjuvant chemotherapy.

\section{Discussion}

The 5-year survival rate for all gastric carcinoma patients undergoing surgery is only $20 \%$ to $30 \%$. Local recurrence has been reported to be the main cause of treatment failure [7]. When T4 gastric carcinoma has invaded the surrounding tissues and organs, curative resection is achieved in only $33.3 \%$ of cases, although patients who undergo tumor resection (either curative or noncurative) have a significantly better survival rate than those who do not undergo resection [8].

During the last 20 years, preoperative chemotherapy has been used in an attempt to decrease the gastric tumor recurrence rate and increase the survival rate. The two main goals of neoadjuvant chemotherapy are downstaging the primary tumor to increase the chances of successful complete resection and destroying occult lymph nodes and distant metastases. Patients with clinical response to chemotherapy have significantly better prognoses than those without clinical response, particularly when complete (R0) resection is performed [9-11].

Several chemotherapy regimens have been developed for the treatment of advanced gastric cancer. Superior results have been achieved with epirubicin and cisplatin plus continuous-infusion fluorouracil (ECF). A phase III randomized trial showed that, compared with fluorouracil/ doxorubicin/methotrexate, ECF showed a better overall response rate (ORR) (45\% versus $21 \%$ ), a longer median time to progression (TTP) (7.4 versus 3.4 months), and a longer overall survival (OS) (8.9 versus 5.7 months) [12]. Therefore, the investigators proposed ECF as a standard therapy [12,13]. More recently, several new agents have emerged, including taxanes, irinotecan, and oxaliplatin. Docetaxel was the first agent tried in advanced gastric cancer and showed better activity than the alternatives. Used as a single agent, docetaxel has been reported to have response rates between $17 \%$ and 29\% [14-16]. Combined with other agents, paclitaxel has also shown promise $[17,18]$. The combination regimens, including paclitaxel/5-fluorouracil (5-FU)/cisplatin, resulted in response rates as high as $53 \%$, with a median survival of 7 to 14 months [19-23]. The docetaxel/cisplatin/fluorouracil (DCF) regimen showed efficacy comparable to that of other regimens of cisplatin or anthracycline combinations. In the V325 Study Group, Van Cutsem et al. reported that adding docetaxel to cisplatin and fluorouracil (CF) significantly improved TTP, survival, and response rate in gastric cancer patients [22]. In a randomized phase II trial of the Swiss Group for Clinical Cancer Research, Roth et al. compared the therapy result of DCF with those of docetaxel and cisplatin (DC) and ECF. They reported an ORR of $25.0 \%$ (13 to $41 \%$ ) for ECF, $18.5 \%$ (9 to $34 \%$ ) for DC, and $36.6 \%$ (23 to $53 \%$ ) for DCF $(\mathrm{n}=119)$. Median overall survival times were 8.3, 11.0, and 10.4 months for ECF, DC, and DCF, respectively [23].

Hematotoxicity was the main adverse effect in docetaxel trials for advanced gastric cancer. Roth et al. reported a high incidence of febrile neutropenia associated with the DCF regimen, which occurred in $41 \%$ of patients, compared with only $18 \%$ and $21 \%$ of patients in the ECF and DC arms, respectively [23]. After the dose of docetaxel was reduced, the incidence of febrile neutropenia declined. According to the literature, $75 \mathrm{mg} / \mathrm{m}^{2}$ docetaxel combined with CF is well-tolerated, and this dose of docetaxel is most frequently proposed for treatment of gastric cancer [24-26]. Moreover, a higher incidence of febrile neutropenia did not translate to a higher mortality rate. This toxicity was acceptable, and the neutropenia was easily managed with granulocyte colony-stimulating factor (G-CSF). Interestingly, the higher incidence of toxicity did not appear to affect quality of life and clinical benefits, which were significantly greater with the DCF regimen, possibly because of the higher antitumor activity of DCF [22].

The histologic tumor regression grade is an objective measure of the effects of neoadjuvant chemotherapy. The overall rate of complete clinical response to DCF for advanced gastric tumor is 2 to $4.9 \%$ [22,23]. The rate of complete pathologic response, however, has been unknown.

Rapid tumor reduction before curative surgery is an important indicator of the success of neoadjuvant chemotherapy. Roth et al. reported that a DCF regimen resulted in a shorter median time to treatment response (TTR) than an ECF regimen (median TTR 1.6 versus 3.0 months) [23]. The patient with the T4 gastric tumor described here exhibited a complete pathologic response to DCF chemotherapy in 10 weeks. These results indicate that DCF neoadjuvant chemotherapy is a promising method of treating advanced gastric cancer.

\section{Conclusions}

In conclusion, we observed a case of locally advanced gastric carcinoma, which exhibited a complete histologic response after neoadjuvant chemotherapy; the patient survived for more than 5 years. According to our experience, DCF neoadjuvant chemotherapy is a promising method of treatment for advanced gastric cancer.

\section{Consent}

Written informed consent was obtained from the patient for the publication of this report and any accompanying images. 


\section{Abbreviations}

CF: cisplatin/fluorouracil; CT: computed tomography; DC: docetaxel/cisplatin; DCF: docetaxel/cisplatin/fluorouracil; ECF: epirubicin/cisplatin/fluorouracil; ORR: overall response rate; G-CSF: granulocyte colony-stimulating factor; TTP: time to progression; TTR: median time to treatment response.

\section{Competing interests}

Ming gao Guo and the other co-authors have no competing interest.

\section{Authors' contributions}

MGG, QZ, JZD, ZY participated in the treatment of the patient. All authors read and approved the final manuscript.

Received: 18 August 2013 Accepted: 20 April 2014

Published: 19 May 2014

\section{References}

1. Blanke CD, Corless CL, Schwarz RE, Bonin SR: Gastric Cancer. 9th edition. Lawrence, KS: CMP Healthcare Media; 2005.

2. Hazard $L, O^{\prime}$ Connor J, Scaife C: Role of radiation therapy in gastric adenocarcinoma. World J Gastroenterol 2006, 12:1511-1520.

3. Meyerhardt JA, Fuchs CS: Adjuvant therapy in gastric cancer: can we prevent recurrences? Oncology 2003, 17:714-722.

4. Rossi M, Broglia L, Graniano P, Maccioni F, Bezzi M, Masciangleo R, Rossi P. Local invasion of gastric cancer: $\mathrm{CT}$ findings and pathologic correlation using 5 mm incremental scanning, hypotonia, and water-filling. AJR 1999, 172:383-388.

5. Lee DH, Ko YT, Park SJ, Lim JW: Comparison of hydro-US and spiral CT in the staging of gastric cancer. Clin Imaging 2001, 25:181-186.

6. Japanese Research Society for Gastric Cancer: The general rules for gastric cancer study in surgery and pathology: part I. Jpn J Surg 1981, 11:127-139.

7. Neugut Al, Hayek M, Howe G: Epidemiology of gastric cancer. Semin Oncol 1996, 23:281-291.

8. Kim DY, Joo JK, Seo K, Yeung W, Park ES, Young K, Yu R: T4 gastric carcinoma: the benefit of non-curative resection. WANZ J Surg 2006, 76:453-457.

9. Lowy AM, Mansfield PF, Leach SD, Pazdur R, Dumas P, Ajani JA: Response to neoadjuvant chemotherapy best predicts survival after curative resection of gastric cancer. Ann Surg 1999, 229:303-308.

10. Schuhmacher CP, Fink U, Becker K, Busch R, Dittler HJ, Mueller J, Siewert JR: Neoadjuvant therapy for patients with locally advanced gastric carcinoma with etoposide, doxorubicin, and cisplatinum. Closing results after 5 years of follow-up. Cancer 2001, 91:918-927.

11. D'Ugo D, Persiani R, Rausei S, Biondi A, Vigorita V, Boccia S, Ricci R: Response to neoadjuvant chemotherapy and effects of tumor regression in gastric cancer. Eur J Surg Oncol 2006, 32:1105-1109.

12. Webb A, Cunningham D, Scarffe JH, Harper P, Norman A, Joffe JK, Hughes M, Mansi J, Findlay M, Hill A, Oates J, Nicolson M, Hickish T, O'Brien M, Iveson T, Watson M, Underhill C, Wardley A, Meehan M: Randomized trial comparing epirubicin, cisplatin, and fluorouracil versus fluorouracil, doxorubicin, and methotrexate in advanced esophagogastric cancer. J Clin Oncol 1997, 15:261-267.

13. Waters JS, Norman A, Cunningham D, Scarffe JH, Webb A, Harper P, Joffe JK, Mackean M, Mansi J, Leahy M, Hill A, Oates J, Rao S, Nicolson M, Hickish T: Long-term survival after epirubicin, cisplatin and fluorouracil for gastric cancer: results of a randomized trial. Br J Cancer 1999, 80:269-272.

14. Ajani JA, Fairweather J, Dumas P, Patt YZ, Pazdur R, Mans Weld PF: Phase II study of taxol in patients with advanced gastric carcinoma. Cancer J Sci Am 1998, 4:269-274

15. Cascinu S, Graziano F, Cardarelli N, Marcellini M, Giordani P, Menichetti ET, Catalano G: Phase II study of paclitaxel in pretreated advanced gastric cancer. Anticancer Drugs 1998, 9:307-310.

16. Yamaguchi K, Tada M, Horikoshi N, Otani T, Takiuchi H, Saitoh S, Kanamaru R, Kasai Y, Koizumi W, Sakata Y, Taguchi T, Paclitaxel Gastric Cancer Study Group in Japan: Paclitaxel gastric cancer study group in Japan phase II study of paclitaxel with 3 - $\mathrm{h}$ infusion in patients with advanced gastric cancer. Gastric Cancer 2002, 5:90-95.

17. Cascinu S, Ficarelli R, Safi MA, Graziano F, Catalano G, Cellerino R: A phase I study of paclitaxel and 5-fuorouracil in advanced gastric cancer. Eur $J$ Cancer 1997, 33:1699-1702.

18. Sastre J, García-Saenz JA, Díaz-Rubio E: Chemotherapy for gastric cancer. World J Gastroenterol 2006, 12:204-213.
19. Honecker F, Kollmannsberger C, Quietzsch D, Haag C, Schroeder M, Spott C, Hartmann JT, Baronius W, Hempel V, Kanz L, Bokemeyer C: Phase II study of weekly paclitaxel plus 24-h continuous infusion 5-Xuorouracil, folinic acid and 3-weekly cisplatin for the treatment of patients with advanced gastric cancer. Anticancer Drugs 2002, 13:497-503.

20. Kim YH, Shin SW, Kim BS, Kim JH, Kim JG, Mok YJ, Kim CS, Rhyu HS, Hyun JH, Kim JS: Paclitaxel, 5-Xuorouracil, and cisplatin combination chemotherapy for the treatment of advanced gastric carcinoma. Cancer 1999, 85:295-301.

21. Kollmannsberger C, Quietzsch D, Haag C, Lingenfelser T, Schroeder M, Hartmann JT, Baronius W, Hempel V, Clemens M, Kanz L, Bokemeyer C A phase II study of paclitaxel, weekly, 24-h continuous infusion 5-Xuorouracil, folinic acid and cisplatin in patients with advanced gastric cancer. Br J Cancer 2000, 83:458-462.

22. Van Cutsem E, Moiseyenko VM, Tjulandin S, Majlis A, Constenla M, Boni C, Rodrigues A, Fodor M, Chao Y, Voznyi E, Risse ML, Ajani JA, V325 Study Group: Phase III study of docetaxel and cisplatin plus fluorouracil compared with cisplatin and fluorouracil as first-line therapy for advanced gastric cancer: a report of the V325 study group. J Clin Oncol 2006, 24:4991-4997.

23. Roth AD, Fazio N, Stupp R, Falk S, Bernhard J, Saletti P, Köberle D, Borner MM, Rufibach K, Maibach R, Wernli M, Leslie M, Glynne-Jones R, Widmer L, Seymour M, de Braud F, Swiss Group for Clinical Cancer Research: Docetaxel, cisplatin, and fluorouracil; docetaxel and cisplatin; and epirubicin, cisplatin, and fluorouracil as systemic treatment for advanced gastric carcinoma: a randomized phase II trial of the swiss group for clinical cancer research. J Clin Oncol 2007, 25:3217-3223.

24. Ajani JA, Fodor MB, Tjulandin SA, Moiseyenko VM, Chao Y, Cabral Filho S, Majlis A, Assadourian S, Van Cutsem E: Phase II multi-institutional randomized trial of docetaxel plus cisplatin with or without fluorouracil in patients with untreated, advanced gastric, or gastroesophageal adenocarcinoma. J Clin Oncol 2005, 23:5660-5667.

25. Ridwelski K, Gebauer T, Fahlke J, Kröning H, Kettner E, Meyer F, Eichelmann $\mathrm{K}$, Lippert $\mathrm{H}$ : Combination chemotherapy with docetaxel and cisplatin for locally advanced and metastatic gastric cancer. Ann Oncol 2001, 12:47-51.

26. Philip PA: Experience with docetaxel in the treatment of gastric cancer. Semin Oncol 2005, 32:S24-S38.

doi:10.1186/1477-7819-12-150

Cite this article as: Guo et al:: Histological complete response to a combined docetaxel/cisplatin/fluorouracil neoadjuvant chemotherapy for T4 stage gastric adenocarcinoma. World Journal of Surgical Oncology 2014 12:150

\section{Submit your next manuscript to BioMed Central and take full advantage of:}

- Convenient online submission

- Thorough peer review

- No space constraints or color figure charges

- Immediate publication on acceptance

- Inclusion in PubMed, CAS, Scopus and Google Scholar

- Research which is freely available for redistribution 